University of Nebraska - Lincoln

DigitalCommons@University of Nebraska - Lincoln

5-25-1999

\title{
Z-Protected Glutamic Acid-Based Biodegradable Thermoplastic and Thermosetting Polyesters: Synthesis and Characterization
}

\author{
R M. Tadros \\ Pine Bluff Arsenal, Pine Bluff, Arkansas 71602 \\ Hossein Noureddini \\ Department of Chemical Engineering, University of Nebraska-Lincoln, hnouredd@unlnotes.unl.edu \\ Delmar C. Timm \\ University of Nebraska-Lincoln, dtimm1@unl.edu
}

Follow this and additional works at: https://digitalcommons.unl.edu/chemeng_biomaterials

Part of the Biomaterials Commons

Tadros, R M.; Noureddini, Hossein; and Timm, Delmar C., "Z-Protected Glutamic Acid-Based Biodegradable Thermoplastic and Thermosetting Polyesters: Synthesis and Characterization" (1999). Papers in Biomaterials. 5.

https://digitalcommons.unl.edu/chemeng_biomaterials/5

This Article is brought to you for free and open access by the Chemical and Biomolecular Engineering Research and Publications at DigitalCommons@University of Nebraska - Lincoln. It has been accepted for inclusion in Papers in Biomaterials by an authorized administrator of DigitalCommons@University of Nebraska - Lincoln. 
R. M. Tadros, H. Noureddini, D. C. Timm, Z-Protected Glutamic Acid-Based Biodegradable Thermoplastic and Thermosetting Polyesters: Synthesis and Characterization

Z-Protected Glutamic Acid-Based Biodegradable Thermoplastic and Thermosetting Polyesters: Synthesis and Characterization

R. M. TADROS, H. NOUREDDINI, D. C. TIMM

"This article is a preprint of an article published in (c) Journal of Applied Polymer Science, Vol. 73, Issue 6, 869-879 (1999). Published Online: 25 May 1999 Copyright (C) 1999 John Wiley \& Sons, Inc.CCC 0021-8995/99/060869-11"

This article is available at the publishers site:

http://www3.interscience.wiley.com/cgi-bin/abstract/61501069/ABSTRACT 
R. M. Tadros, H. Noureddini, D. C. Timm, Z-Protected Glutamic Acid-Based Biodegradable Thermoplastic and Thermosetting Polyesters: Synthesis and Characterization

\section{ABSTRACT:}

Biodegradable polymers were formed from $N$-benzyloxycarbonyl-L-glutamic acid with the comonomers ethylene glycol, diglycidyl ether of 1,4-butanediol, and diglycidyl ether of bisphenol $A$. The three polymers were a linear and a rosslinked heterochain polyester and a crosslinked polyester that contained aromatic units within its network chains. The thermoplastic resin and the soluble fractions for the thermosetting resins were characterized by gel permeation chromatography. Conversions for carboxylic acid were determined by titrations. A quality, 22,000 molecular weight thermoplastic resin was formed. The two thermosets were cured past their gel points. Gelation analysis revealed that the relative rate constants for the sequential oxirane/ acid and alcohol/acid reactions were distinct. With diglycidyl ether of 1,4butanediol, the ratio of the respective rate constants was 3; with diglycidyl ether of bisphenol $A$, the ratio approached 200. The resins hydrolyzed to monomers in the presence of lipase, but in the presence of a mixed microbial culture, only the first two resins decayed to biomass, respiratory gases, and water. The third resin was inert during the period of observation.

Key words: amino-protected glutamic acid; biodegradable polymers; gelation; polymer networks; polyesters

\section{INTRODUCTION}

The development of biodegradable polymers using value-added, renewable agricultural resources was a prime motivation for this research. Annually, an enormous tonnage of plastics is sent to wastedisposal systems, such as landfills. Synthetic, organic polymers resist natural degradation

due to variables that include a low surface area per unit mass, chemical structure, and high molecular weight. Degradation may be initiated through environmentally induced changes which transform the polymer into smaller segments. To be classified as biodegradable, these fragments should decay via microorganisms into biomass, respiratory gases, and water. In tertiary recycling, polymers decay to monomers.1 Potential uses of biodegradable polymers include controlled release formulations for drugs, the preparation of surgical implants, agricultural chemicals, and agricultural mulch. In this article, the synthesis and characterization of three quality polymers with distinct chain configurations is addressed. Companion articles discuss the results of biodegradation studies. Soybean protein and its derivatives were a focus of polymer research in the 1930s and 1940s. Today, proteins are used to form grafted, synthetic copolymers as well as protein-based biodegradable plastics. 2 In general, mixed monomers reduce a plastic's physical properties. Therefore, instead of using complex protein molecules, glutamic acid was selected to produce resins with regular chain configurations. Glutamic acid is a major component of oilseed proteins, representing the order of $20 \%$ of their amino acid content. Several methods are available for separating glutamic acid from hydrolyzed amino acids.3-5 It is also produced by fermentation. In addition, poly(L-glutamic acid) is a biodegradable material6 and a block copolymer between poly(g-ethyl-Llutamate) and polybutadiene is biocompatible as well as biodegradable.7 A review of the literature regarding biodegradability further directed the research toward the chemical design and synthesis of polyesters.8 Glutamic acid is an a-amino acid containing two carboxylic acids and one amino group. Heating glutamic acid with a diol can result in the formation of a cyclic amide, a five-member lactam. In addition, dipeptides easily cycle to sixmember diketopiperazines. These are major side reactions encountered in peptide synthesis.9,10 In

our work, oligomeric-forming side reactions were observed to occur in abundance. Cyclization was controlled through protection of the a-amino group using benzyloxycarbonyl ( $Z$ ) (see Fig. 1). Different amino-protecting groups were discussed by Jones.9 Since polyesterifications are acid-catalyzed reactions, the benzyloxycarbonyl group (ArOCH2OOOCOO) was selected due to its stability under acidic conditions.11 Comonomerstructures also appear in Figure 1. as an acid or as a base in an aqueous medium of different $\mathrm{pH}$. The suitable $\mathrm{pH}$ for activating the acid form of the amino acid is lower than the 
R. M. Tadros, H. Noureddini, D. C. Timm, Z-Protected Glutamic Acid-Based Biodegradable Thermoplastic and Thermosetting Polyesters: Synthesis and Characterization

isoionic point for each ionization group. In acidic aqueous media, the amino acid is an active acid and thus directs a synthesis to

ward forming polyesters with dioles. Pramanick and Rey12 reported the formation of a 4000 molecular weight polymer with ethylene glycol in an aqueous acidic medium. Since our goal was to synthesize higher molecular weight resins, we did not explore this avenue. Bulk polymerizations with protected amino acids were selected. For the second monomers, a diol and diepoxies were chosen. The diol yields a thermoplastic; diepoxies yield thermosets. An epoxy moiety initially opens during the polymerization, forming a hydroxyl group and an ester linkage. The hydroxyl site then couples with a second carboxyl group, forming a second ester bond and water. The functionality for a diepoxy monomer is four, and networks form (see Fig. 2). In this sketch, functionality is emphasized. The diepoxy branch node is represented by a tetrafunctional chain link. The amino acid is expressed by a bifunctional chain link. The order for reactions is labeled 1st and 2nd, arbitrarily, for discussion. On the upper right, an unreacted epoxy is represented by two unreacted branches; at the lower right, an unreacted alcohol is indicated by one unreacted branch. In the interior of the sketch, both the oxirane and formed alcohol have reacted. Variables appearing on the sketch will be discussed in the section on gelation. The Z-protecting group is not indicated but is pendent to the bifunctional chain links.

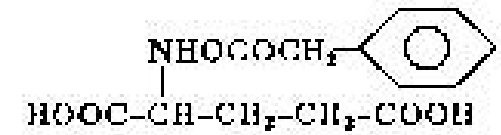

Z Elackas Glatanic Acid (ZGluOH)
$\mathrm{HO}-\mathrm{ClI}_{2}-\mathrm{CHI}_{2}-\mathrm{OHI}$

Ethylene G]ys:o] [EG)

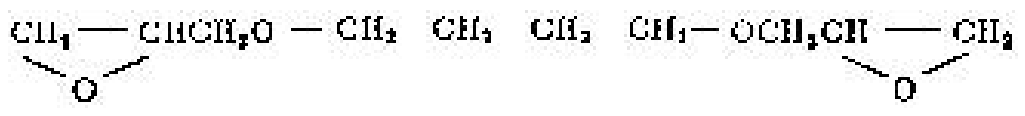

Digiycidyl Elkex of 1,4-Butrujecijol (BDE)

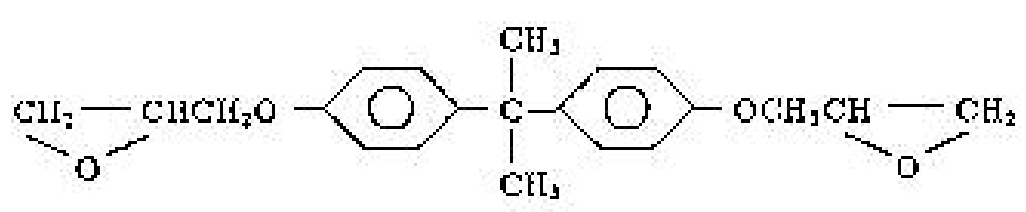

Digycidyl Eluser of Bispluesol a (DGEliA)

Fig. 1 Chemical formulas for Monomers 
R. M. Tadros, H. Noureddini, D. C. Timm, Z-Protected Glutamic Acid-Based Biodegradable Thermoplastic and Thermosetting Polyesters: Synthesis and Characterization

\section{EXPERIMENTAL}

\section{Materials}

glycol

Benzyloxycarbonyl-L-glutamic acid $(\mathrm{ZGluOH})$ and L-glutamic acid (HGluOH) (Aldrich), ethylene

(EG; Fisher), diglycidyl ether of 1,4-butanediol (DGEB; Ciba Chemical), and diglycidyl ether of bisphenol A (DGEBA; Shell Chemical) were used as received. Tetrahydrofuran (THF; Quaker Oats) was the mobil phase during GPC fractionations. In studies designed to address the thermal stability of the $Z$ protection, the monofunctional 1-nonanol (Aldrich) was reacted with ZGluOH. Fractionations used reversed-phase high-performance chromatography (HPLC). The mobil phase was a gradient of acetonitrile (Aldrich) and water. The catalyst was $p$-toluene sulfonic acid (PTS).

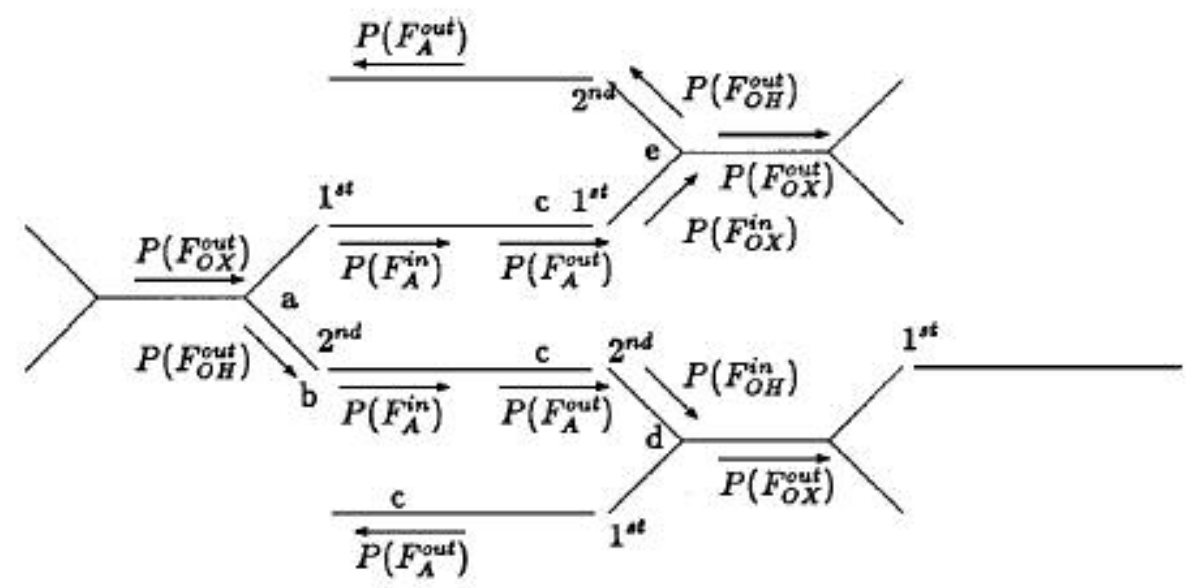

Fig. 2 A Cluster of network chain segment, Stochastic gel structural parameters related to ribber elasticity for arbitrary oxirane first and hydroxyl second reactions.

\section{Thermal Stability of the Amino Protection}

In discussing the thermal stability of urethanes, Stevens 13 stated that a polycarbamate derived from aliphatic-based monomers can be melt-processed at $180^{\circ} \mathrm{C}$, but warns that the higher temperatures needed for melt polymerization of resins formulated with aromatic diisocyanates tend to cause dissociation into alcohol and isocyanate or degradation into amines, olefins, and carbon dioxide. In our formulations, alcoholysis was of concern. To examine the stability of the Z-protecting group, a carbamate, the reaction between ZGluOH and the monofunctional alcohol 1-nonanol was studied using HPLC. Batch reactions with 
R. M. Tadros, H. Noureddini, D. C. Timm, Z-Protected Glutamic Acid-Based Biodegradable Thermoplastic and Thermosetting Polyesters: Synthesis and Characterization

formulations based on stoichiometry ratios of acids/alcohols at $170^{\circ} \mathrm{C}$ and atmospheric pressure were conducted. The condensation product water was allowed to escape from the reactor. If appreciable levels of alcoholysis occurred, esters of varying chemical composition would be observed through fractionations. In

a 2-h interval, the formation of mono- and diesters was readily observed. Similar compounds formed in the presence of alcoholysis were not observed. Therefore, we concluded that the major polymerization site would be the carboxylic acid moiety. A Waters chromatograph was used with a mbondapak C18 column, $3.93300 \mathrm{~mm}$. The gradient of 40-90\% acetonitrile/water was conducted over $1 \mathrm{~h}$. An ultraviolet detector at $280 \mathrm{~nm}$ was used. The reaction was catalyzed with PTS.

\section{Polymerization Procedures Thermoplastic Resin}

In an initial polymerization, HGluOH/EG/PTS was melt-mixed with a molar ratio of $1 / 1 / 0.01$. The polymerization proceeded by amidization/esterification reactions. Water was stripped under a vacuum $(400 \mathrm{mmHg})$ from a batch reactor to shift the chemical equilibrium toward higher conversions. 1,14 A slow stream of inert gas (N2) was bubbled through the molten mix to assist with moisture removal and to limit resin oxidation.

The reaction temperature was maintained within $1^{\circ} \mathrm{C}$ of the set point, $170^{\circ} \mathrm{C}$. This procedure was then modified by melt-mixing ZGluOH/EG/PTS with a stoichiometric ratio of $1 / 1.08 / 0.01$. In latter stages of the cure, excess ethylene glycol was stripped from the reactor during transesterification reactions. 1 Isothermal cure temperatures were 110 and $170^{\circ} \mathrm{C}$. Samples $(.0 .1 \mathrm{~g})$ were analyzed through end-group analysis and gel permeation chromatography (GPC).15,16 The reactor apparatus consisted of a 100-cc round, Pyrex glass flask. A glass tube about $10 \mathrm{~cm}$ long was used to admit a stream of nitrogen to bubble through the molten resin. Another tube was used for removing samples. A type-K thermocouple allowed temperatures to be observed. The apparatus was heated in a temperature-regulated liquid bath.

\section{Thermoset Resins}

ZGluOH/diepoxy/PTS polyesters were prepared by melt-mixing the molar ratios of 1.0/1.0/0.02. To limit the extent of crosslinking, the acid group was selected as the limiting reactive site. The polymer mix was initially placed into a $50-\mathrm{mL}$ forcedair, electric oven. The chosen, set-point temperatures ranged between 110 and $130^{\circ} \mathrm{C}, 60.5^{\circ} \mathrm{C}$. After 15 min of preheating, approximately $5 \mathrm{~mL}$ of the molten mixture was poured into each $10-\mathrm{mL}$ glass tube. The tubes were placed in the oven at the same initial temperature. At different time intervals, a polymerization sample was withdrawn and thermally quenched. The oven was blanketed with nitrogen. 
R. M. Tadros, H. Noureddini, D. C. Timm, Z-Protected Glutamic Acid-Based Biodegradable Thermoplastic and Thermosetting Polyesters: Synthesis and Characterization

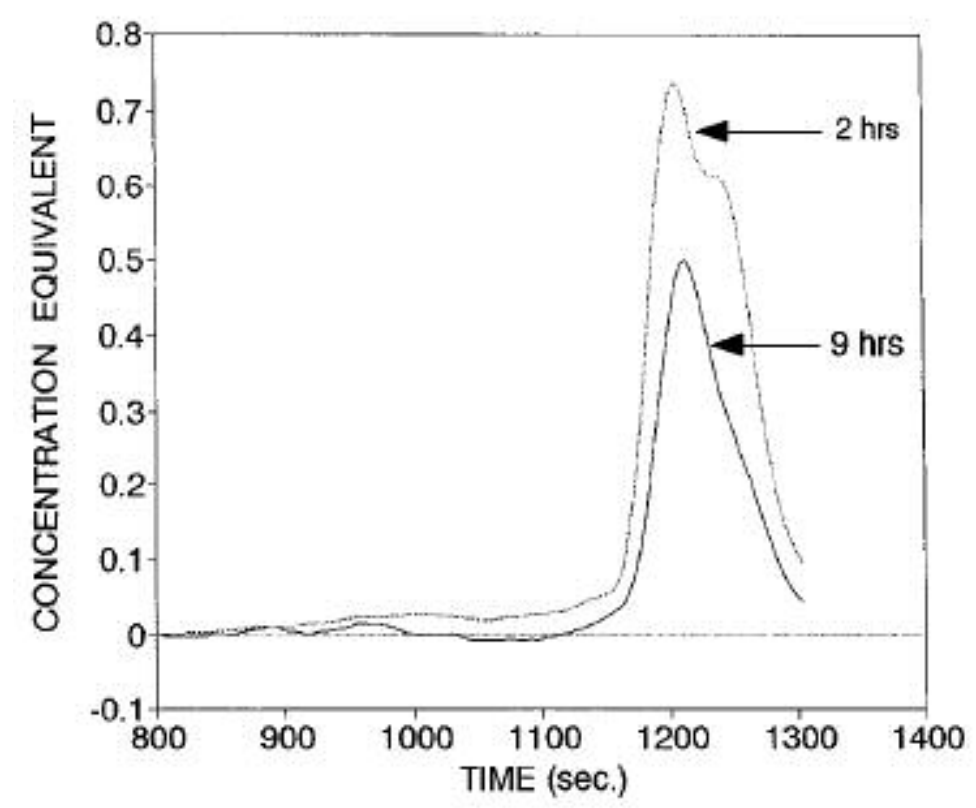

Fig. 3 Ethylene glycol - glutamic acid cyclization

\section{Characterization}

\section{Gel Permeation Chromatography}

A Waters GPC was equipped with five Ultrastyragel columns of 23100,500 , and $231000 \AA$ and a differential refractometer. The mobil THF phase was at $0.5 \mathrm{~mL} / \mathrm{min}$. Fractionations were at ambient temperature. For miscible materials, $75 \mathrm{mg}$ was dissolved in $50 \mathrm{~mL}$ of THF and $0.5 \mathrm{~mL}$ of this solution was injected. For thermosets, between 0.2 and $0.3 \mathrm{~g}$ was placed with $20 \mathrm{~mL}$ of THF in a cylindrical, thick-walled brass container and extracted at a temperature in excess of the specimen's glass transition temperature $(\mathrm{Tg})$. The insoluble gel fraction was dried at $70^{\circ} \mathrm{C}$ under a vacuum and weighed. The soluble sol fraction was diluted to approximately $75 \mathrm{mg}$ in $50 \mathrm{~mL}$ of THF for analysis. The average molecular weight of the oligomeric fraction was compared to a polystyrene semilogarithmic correlation of the standard's molecular weight as a function of its peak elution volume.

\section{End-Group Analysis}

On average, a linear polymeric chain has a single carboxylic group. The carboxylic groups in the resin were titrated against $\mathrm{KOH}$ using phenolphthalein as an indicator. The polymer samples were dissolved in $50 \mathrm{~mL}$ of chloroform. The $\mathrm{KOH}$ was dissolved in methyl alcohol to form a $0.01 \mathrm{~N} \mathrm{KOH}$ solution. A clear, sharp, color change occurred at the end point. To measure conversion, a similar procedure was 
R. M. Tadros, H. Noureddini, D. C. Timm, Z-Protected Glutamic Acid-Based Biodegradable Thermoplastic and Thermosetting Polyesters: Synthesis and Characterization

followed for the thermosets. Samples were initially finely ground and allowed to swell in the solvent before titration. Titrations were conducted over an interval of time under nitrogen until the end point became stable for at least $24 \mathrm{~h}$.

\section{DATA ANALYSES}

\section{Linear Resins}

\section{Reaction Dynamics}

For the HGluOH/EG/PTS resin, samples collected at different times were screened by GPC. Samples cured for 2 and $9 \mathrm{~h}$ indicated a minimal change in molecular weight (see Fig. 3). Molecular weights were close to that for the monomers. Cyclic structures likely formed.9,10 ZGluOH/EG/PTS was polymerized under the same conditions. With the protected amine group, molecular weight advanced. A quality resin formed. In Figure 4, shifts in chromatograms reveal the development of polymeric materials with advancing cure time.

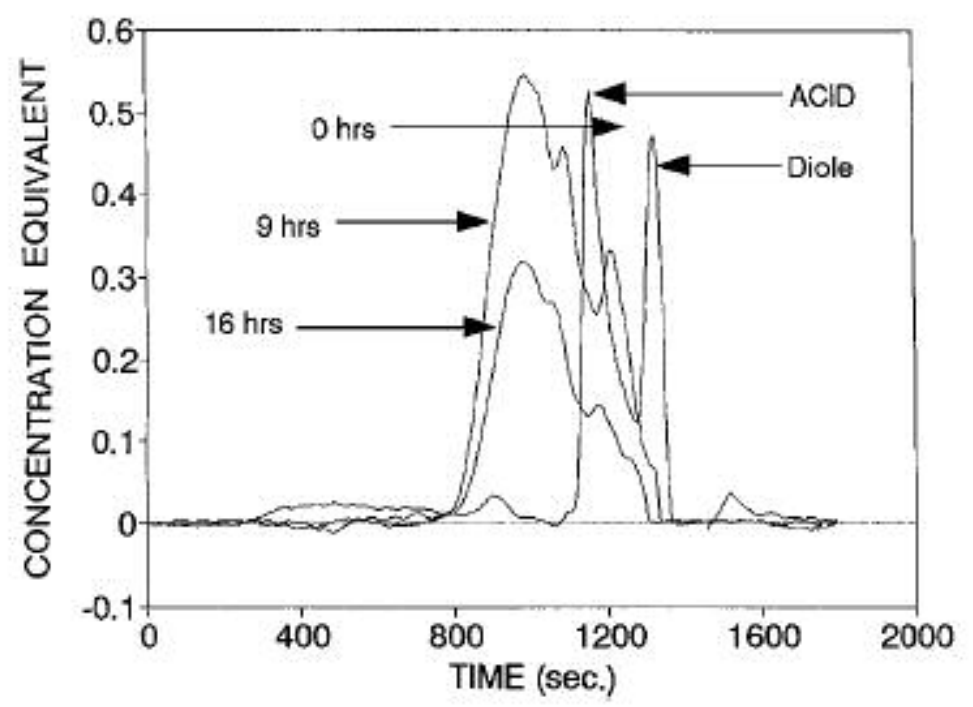

Fig.4 Development of polymers using Z- protected glutamic acid. 
R. M. Tadros, H. Noureddini, D. C. Timm, Z-Protected Glutamic Acid-Based Biodegradable Thermoplastic and Thermosetting Polyesters: Synthesis and Characterization

Table 1

\begin{tabular}{cccc}
\hline $\begin{array}{c}\text { Time } \\
\text { (h) }\end{array}$ & $\begin{array}{c}\text { Carboxylic } \\
\text { Group } \\
\text { (mol/g polymer) }\end{array}$ & $\begin{array}{c}\text { Extent } \\
\text { of Reaction }\end{array}$ & $\begin{array}{c}\text { Average } \\
\text { Molecular } \\
\text { Weight }\end{array}$ \\
\hline 0 & 0.0079 & & \\
0.5 & 0.0063 & 0.208 & 440 \\
1 & 0.0060 & 0.236 & 455 \\
1.5 & 0.0058 & 0.271 & 480 \\
2 & 0.0055 & 0.299 & 495 \\
3 & 0.0053 & 0.326 & 515 \\
6 & 0.0051 & 0.356 & 540 \\
9 & 0.0047 & 0.408 & 585 \\
12 & 0.0043 & 0.461 & 640 \\
15 & 0.0042 & 0.467 & 650 \\
18 & 0.0035 & 0.557 & 780 \\
24 & 0.0033 & 0.582 & 830 \\
\hline
\end{tabular}

Conversion and Number-Average Molecular Weight Dynamics, ZGluOH/BDE/PTS Cured at $110^{\circ} \mathrm{C}$ 
R. M. Tadros, H. Noureddini, D. C. Timm, Z-Protected Glutamic Acid-Based Biodegradable Thermoplastic and Thermosetting Polyesters: Synthesis and Characterization

Table 2

\begin{tabular}{cccr}
\hline $\begin{array}{c}\text { Time } \\
\text { (h) }\end{array}$ & $\begin{array}{c}\text { Carboxylic } \\
\text { Group } \\
\text { (mol/g polymer) }\end{array}$ & $\begin{array}{c}\text { Extent } \\
\text { of Reaction }\end{array}$ & $\begin{array}{c}\text { Average } \\
\text { Molecular } \\
\text { Weight }\end{array}$ \\
\hline 0 & 0.0079 & & \\
2 & 0.0019 & 0.760 & 1450 \\
4 & 0.0013 & 0.835 & 2100 \\
6 & 0.0009 & 0.886 & 3000 \\
8 & 0.0006 & 0.928 & 4800 \\
10.25 & 0.0002 & 0.975 & 14,000 \\
16 & 0.0001 & 0.984 & 22,000 \\
\hline
\end{tabular}

Conversion and Number-Average Molecular Weight Dynamies, ZGluOH/DGEBA/ PTS Cured at $170^{\circ} \mathrm{C}$

\section{End-Group Analysis}

The conversion of acid sites $r$ may be expressed in terms of the cumulative molar concentration of molecules within the resin:

$$
\rho=\frac{P_{1}(0)-\sum P_{i}}{P_{1}(0)}
$$

The molar concentration of all molecules that contain $i$ monomeric links is Pi. If $i$ is even, the molecule contains one unreacted carboxylic group and one unreacted alcohol group. When $i$ is odd, half of these molecules contain two acid sites or two alcohol moieties. Subject to a balanced stoichiometry, their molar concentrations are equal. On average, each molecule of degree of polymerization $i$ contains one acid group.

The number-average molecular weight is

$$
M W_{n}=M W /(1-\rho)
$$

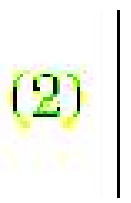

where the average molecular weight of the chain link is $M W$. The data tabulated in Tables I and II summarize the end-group dynamics, the calculated extents of reaction [eq. (1)], and the resins' numberaverage molecular weights [eq. (2)] for cures at 110 and $170^{\circ} \mathrm{C}$ as functions of time. After $16 \mathrm{~h}$ at $170^{\circ} \mathrm{C}$, a quality polymer with a molecular weight of 22,000 had formed. Polymerization dynamics did not yield expected second-order responses. 17 Conversion data correlate as a semilogarithmic function of time 
R. M. Tadros, H. Noureddini, D. C. Timm, Z-Protected Glutamic Acid-Based Biodegradable Thermoplastic and Thermosetting Polyesters: Synthesis and Characterization

(see Fig. 5), with correlation coefficients of 0.97 at $110^{\circ} \mathrm{C}$ and 0.94 at $170^{\circ} \mathrm{C}$. Several factors could contribute to a pseudo-, first-order reaction. Initially, reaction rate constants were considered. Flory 17 observed that rate constants for esterification reactions are dependent on the number of atoms separating carboxyl groups when these atoms are few in number. For the current resin, only three carbon atoms separate the functional groups. Due to electron shielding and steric factors, the first reacting chemical moiety could experience a distinct rate constant.18 A second consideration is attributed to rate constants becoming conversion-dependent. At higher conversions, reaction rates, change for example, due to vitrification 19 and to changing dielectric constants.20 Finally, chemical equilibrium was addressed. Physical operating conditions can affect observations. In our research, the concentration of the condensation product $C$ was not controlled or observed. But with increasing reaction times and diminishing rates of formation, its concentration could have varied.

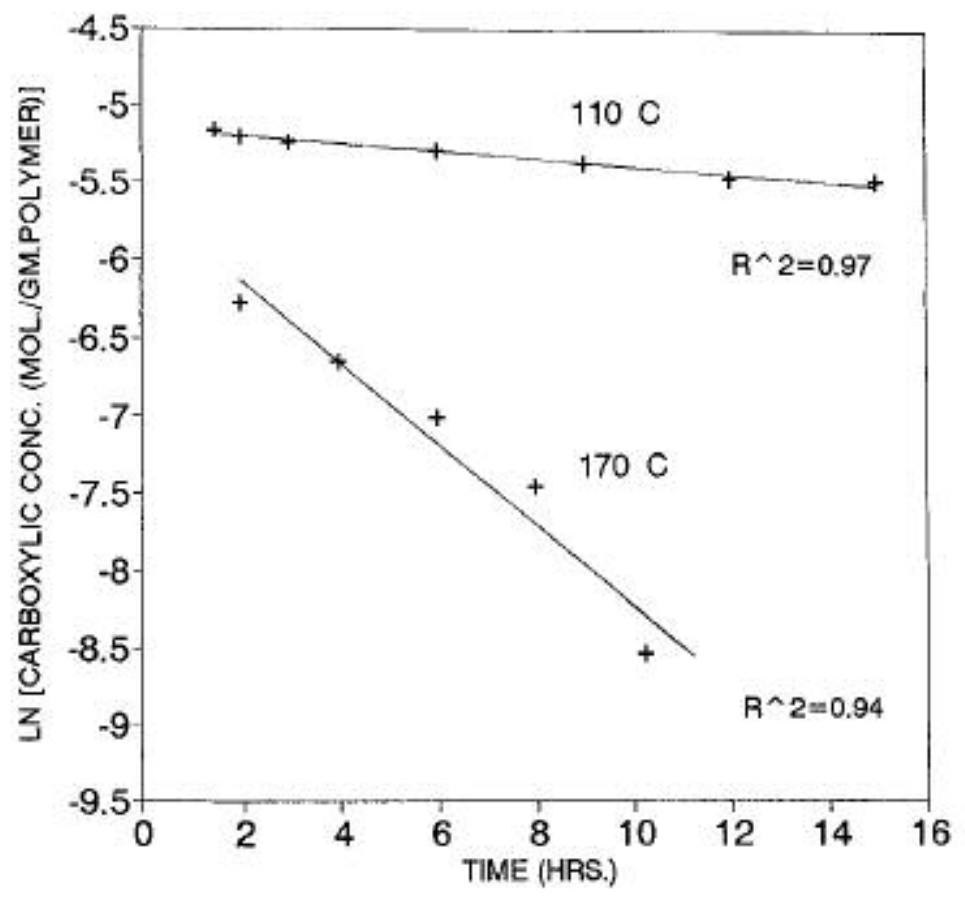

Fig. 5 Carboxylic acid conversion as a funcion of time and reation temparature. 
R. M. Tadros, H. Noureddini, D. C. Timm, Z-Protected Glutamic Acid-Based Biodegradable Thermoplastic and Thermosetting Polyesters: Synthesis and Characterization

To illustrate the consequences of a variable concentration $C$, equilibrium reactions $P i 1 P j{ }^{\circ} P i 1 j 1 C$ are addressed. Stockmayer21 and Blatz and Tobolsky22 showed that the most probable distribution is appropriate for both equilibrium and for kinetically controlled, irreversible reactions. The equilibrium population of molecules may be expressed as a function of monomer concentration $P 1$, the ratio of the equilibrium constant and the by-product concentration $K / C$, and conversion $p_{\text {eq: }}$

$$
P / P_{1}-\left(R P_{1} / C\right)^{2}-\mu_{\text {cot }}^{2}
$$

If equilibrium reactions between oligomers are initially considered, the resulting relationship also fits the above, arbitrary bimolecular reaction. The relationships $M W n / M W=5 \sum i P i / \sum P i=1 /\left(1-K P_{1} / C\right)$ and eq. (2) were utilized in deriving the second result above. One can see that if the ratio $K / C$ varied during an experiment experimental observations will deviate from the most probable distribution. We believe this could be a major contributor to our observations.

\section{Network Resins}

With epoxy monomers, the two oxiranes are separated by a sufficient number of atoms so that their reactivities are independent of oxirane reaction states. This has been confirmed with DGEBA.18 For mathematical simplicity23-25 and due to limited data, the chemical reactivities of the two acid groups on ZGluOH were also assumed to be independent of their reaction states. Flory's data indicate that rate constants gradually change with the number of carbon atoms separating the functional groups. As will be discussed, our results indicate substantial changes. Our analysis was constrained to distinct reactivities for oxiranes and alcohols only. Derivations implicitly incorporate vitrification constraints on kinetic constants as reported by Cole19:

$$
K(\rho)=\frac{K_{0}}{1+\exp \left[\alpha\left(\rho-\rho_{c}\right)\right]}
$$

This function of conversion indicates that the reaction constant $K(r)$ is nearly constant at $K 0$ for $r$, $r c$, but rapidly decreases at high conversions. The constant $a$ is a data-fitting parameter. Cole assumed reactions to be second-order and irreversible.

\section{Crosslinked Polyesters}

ZGluOH/BDE/PTS produced a ductile resin at room temperature with soluble sol and insoluble gel fractions. The chromatograms appearing in Figure 6 show an increasing molecular weight with time of cure at $110^{\circ} \mathrm{C}$ for a resin before its gel point. Resins cured at $130^{\circ} \mathrm{C}$ for $5 \mathrm{~h}$ resulted in a $12 \%$ gel fraction, and for $11.5 \mathrm{~h}$, in a $20 \%$ gel fraction. The crosslinked aromatic polyester, ZGluOH/DGEBA/PTS, was cured at 110,120 , and

$130^{\circ} \mathrm{C}$. Chromatograms appearing in Figure 7 show a gradual increase in the molecular weight of the sol with time of cure at $110^{\circ} \mathrm{C}$. Lower molecular weight materials in the elution time interval 1000-1300 s diminish in concentration; higher molecular weight materials appear prior to $1000 \mathrm{~s}$. The resin cured at $130^{\circ} \mathrm{C}$ for $5 \mathrm{~h} 40 \mu$ yielded a $50 \%$ gel fraction. At ambient conditions, the material is hard and brittle.

\section{Reaction Kinetics}


R. M. Tadros, H. Noureddini, D. C. Timm, Z-Protected Glutamic Acid-Based Biodegradable Thermoplastic and Thermosetting Polyesters: Synthesis and Characterization

A combined kinetic and statistical model was used in the analyses of the thermosetting resins. Distinct rate constants $\mathrm{kOX}$ and $\mathrm{kOH}$ were assigned to reactions between an epoxy or oxirane and a carboxylic acid and between an alcohol and an acid. These rate constants were assumed to be independent of the degree of polymerization. In addition, the isothermal reactions were assumed to be void of intermolecular cyclization reactions. Previous work by Bokar and Gandhi,23 Gupta and Macosko,24 and Sarmoria and Miller25 addressed an amine-cured epoxy when rate constants for primary and secondary amines are distinct with a competing etherification of epoxy groups. Our description26 is a simplification, in that this minor competing reaction is neglected. Dušek et al.27 also considered these reactions and formulated a solution using probability-generating functions.

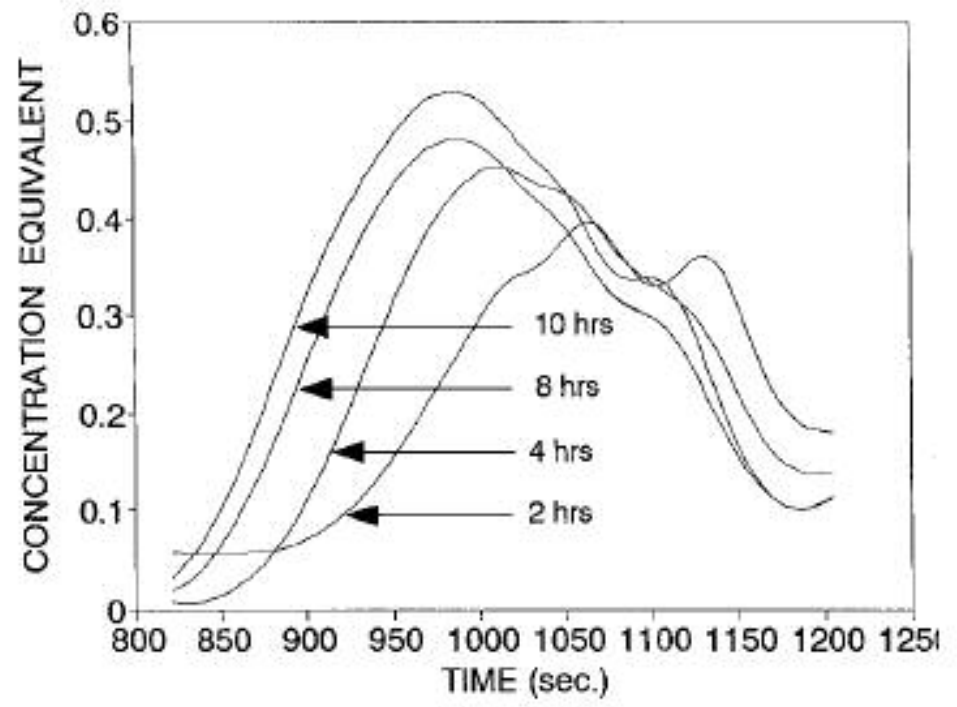

Fig 7 ZGlu OHIDGEBAIPTS plymerization dynamics prior to gelation $110^{\circ}$

Hydroxyl groups originate from the initial reaction between the carboxylic acid and oxirane moieties. Their reactions produce branch nodes and, ultimately, chain networks. The concentrations of the reactive groups (oxiranes, hydroxyls, and carboxylic acids) are represented by $[O X],[O H]$, and $[A]$. The differential equation describing the molar concentration of oxiranes is 
R. M. Tadros, H. Noureddini, D. C. Timm, Z-Protected Glutamic Acid-Based Biodegradable Thermoplastic and Thermosetting Polyesters: Synthesis and Characterization

The time $t$ was transformed to the dimensionless time $\mathrm{t}$ by

$$
d_{T}=k_{O X}[A] d t
$$

The solution, subject to the initial condition $[O X]_{0}$, is

$$
[O X]=[O X]_{0} \exp (-\mathrm{T})
$$

Therefore, the conversion of oxiranes equals

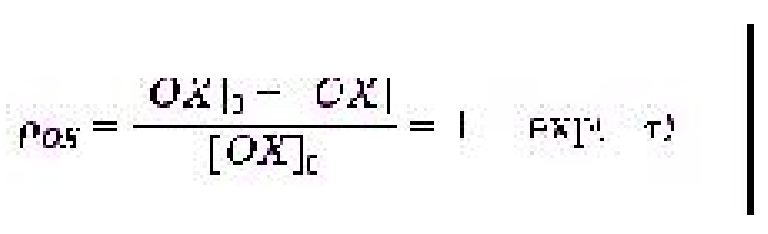

Differentiation plus algebra yield a time-conversion transformation:

$$
k_{o X}[A] d t=d \tau=d \rho_{O X} /\left(1-\rho_{O X}\right)
$$

The concentration of hydroxyl moieties was expressed in terms of a relative rate constant $C$, formulation parameter a, and conversion:

$$
C=\frac{k_{U H}}{k_{O X}} \quad \text { and } \alpha=\frac{[O X]_{0}}{[A]_{0}}
$$

For a balanced stoichiometry, a 512 . In our polymerizations, carboxylic acid sites were limiting, a 51 . The differential equation describing the molar concentration of hydroxyl sites is

$$
d[O H] / d t=-k_{O H}[A][O H]+k_{O X}[A][O X]
$$


R. M. Tadros, H. Noureddini, D. C. Timm, Z-Protected Glutamic Acid-Based Biodegradable Thermoplastic and Thermosetting Polyesters: Synthesis and Characterization

In the first rate term, the consumption of the hydroxyl groups by reactions with carboxylic groups is addressed. The second rate expression describes the formation of hydroxyls by reactions between carboxylic acids and oxiranes. The total number of hydroxyl sites formed at any time equals the number of oxiranes reacted [OX]OrOX. The solution incorporated an integration factor and is expressed in terms of the hydroxyl conversion
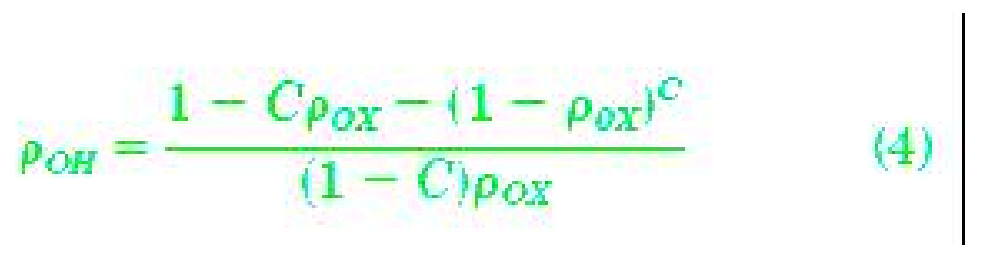

The differential equation describing the molar concentration of carboxylic acids is

$$
d[A] / d t=-k_{O H}[A][O H]-k_{O X}[A][O X]
$$

The rate expressions describe the consumption of carboxylic groups by reactions with hydroxyl groups and oxiranes, respectively. The solution expressed in conversion $\mathrm{r} A$ is

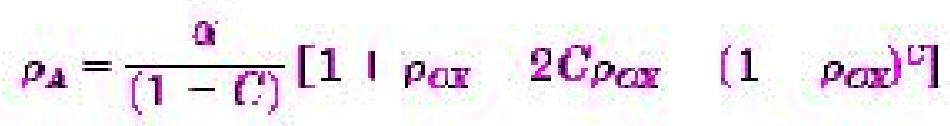

\section{Expectation Theory}

Probability functions express the expectation that a reactive site is attached to chain segments of finite dimension, given all possible events. The sketch of a chain segment appearing in Figure 2 is referenced in the following derivation: Chain functionality is emphasized. The epoxy monomer is described as the tetrafunctional link and the bifunctional $\mathrm{ZGluOH}$ is described as the linear connector. An oxirane site on a branch node at $a$ is considered. The probability that it is attached to chains of finite dimension looking out of the branch node is represented by $P(F O X$ out). If the oxirane originally at $a$ is unreacted (probability of 12 $\mathrm{rOX}$ ), the chain terminates. Alternately, the oxirane is reacted (probability of rOX). The probability function looking into the ester bond formed (labeled 1st in Fig. 2) is indicated as $P(F A$ in). The likelihood that the 
R. M. Tadros, H. Noureddini, D. C. Timm, Z-Protected Glutamic Acid-Based Biodegradable Thermoplastic and Thermosetting Polyesters: Synthesis and Characterization

formed hydroxyl is also part of a finite chain extension $P(F O H$ out ) must also be addressed. Therefore, the expectation that a randomly selected oxirane leads to two finite chain segments at this branch point is

$$
P\left(F_{O X}^{m i t}\right)-1-p_{O X}+p_{O X} P\left(F_{A}^{i n}\right) P\left(F_{O H}^{m i t}\right)
$$

The expectation that a hydroxyl site is connected to a finite chain extension $P(F O H$ out) at $b$ depends on its reaction state. The probability that this group is unreacted equals $12 \mathrm{rOH}$. If it is reacted, the probability is $\mathrm{rOH}$. In Figure 2, this site is labeled $b$. Therefore,

$$
P\left(F_{\text {OH }}^{\text {out }}\right)=1-\rho_{O H}+\rho_{O H} P\left(F_{A}^{\text {in }}\right)
$$

When looking into a bifunctional connecting link, the likelihood that this reacted site is part of a finite chain segment $P(F A$ in) equals the probability $P(F A$ out) that its second acid site is attached to finite structures:

$$
P\left(F_{A}^{\text {in }}\right)=P\left(F_{A}^{\text {eut }}\right)
$$

The reaction state of this second acid site is a function of three independent events: (1) The carboxylic acid may be unreacted (probability of $12 \mathrm{ra}$ ). (2) The acid group may have reacted with an oxirane. This event is labeled 1st at location $c$ in Figure 2. The quantity arOX equals the number of reacted oxiranes per carboxylic acids initially present. The fraction of reacted acid sites is $r A$. This yields the second term in eq. (9). (3) The acid site reacted with a hydroxyl group. This event is represented by point $c, 2$ nd. The quantity arOX also equals the number of hydroxyl sites that have formed at the time of observation, relative to the initial concentration of acid groups. The fraction of hydroxyl sites reacted is $\mathrm{rOH}$. This event contributes the last expression in the conditionalprobability function $P(F A$ out):

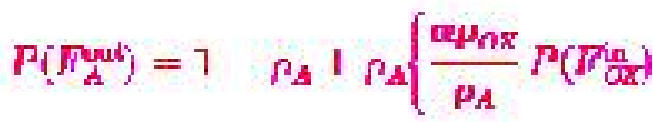

$$
\begin{aligned}
& \left.+\frac{a \rho_{\text {oxpanf }}}{P_{A}} P\left(F_{n+1}^{n}\right)\right\}
\end{aligned}
$$


R. M. Tadros, H. Noureddini, D. C. Timm, Z-Protected Glutamic Acid-Based Biodegradable Thermoplastic and Thermosetting Polyesters: Synthesis and Characterization

When a branch node is entered from a reacted hydroxyl as at point $c, 2$ nd, the likelihood that the exiting two chain segments are finite is labeled $P(F O H$ in $)$. The probability that finite structures are attached at the second oxirane of the tetrafunctional link is $P\left(F^{\text {out }}{ }_{O X A}\right)$. The probability of a finite chain extension at the reacted oxirane branch point is $P\left(F_{\mathrm{OH}}^{A}\right)=P\left(F_{\text {ox }}^{\text {out }} P\left(F_{A}^{\text {out }}\right)\right.$

$$
P_{i} F_{O H}^{\text {in }} !=P_{\left(F_{O X}\right.}^{\text {out }} P_{\left(F_{A}^{\text {out }}\right)}
$$

Alternately, a branch node is entered from a reacted acid site through the bond that formed when the oxirane reacted (see point $c$, 1st). The resulting branch point leads to conditional probability functions $P$ (FOXout) at the second oxirane and $P(F O H$ out $)$ at the formed hydroxyl. Point $e$ may be referenced. For these independent events,

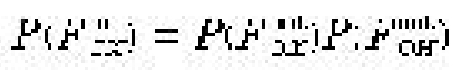

Equations (6)-(11) yield a cubic equation with roots $P(F A$ out $)=1$ and

$$
\begin{aligned}
P\left(F_{A}^{\text {out }}\right) & =-\frac{\alpha \rho_{O X}^{2} \rho_{O H}\left(3-\rho_{O H}\right)}{4 \alpha \rho_{O X}^{2} \rho_{O X}^{2}} \\
+ & \frac{\sqrt{\begin{array}{c}
\left(\alpha \rho_{O X}^{2} \rho_{O H}\left(3-\rho_{O H}\right)\right)^{2}-4\left(2 \alpha \rho_{O X}^{2} \rho_{O H}^{2}\right) \\
\times\left(\alpha \rho_{O X}^{2}\left(1-\rho_{O H}\right)^{2}+2 \alpha \rho_{O X} \rho_{O H}-1\right)
\end{array}}}{4 \alpha \rho_{O X}^{2} \rho_{O H}^{2}}
\end{aligned}
$$

when $\mathrm{p}>\mathrm{p}_{c}, P\left(F_{A}^{\text {out }}\right)<1$, and when $\mathrm{p} \leq \mathrm{p}_{c}, P\left(F_{A^{\text {out }}}\right)=1$, since all chains are finite. Therefore, eq. (12) may be evaluated for the critical conversion $r c$ for gelation. For example, if $C=2.0$ and $P\left(F_{A}^{\text {out }}\right)=1, \mathrm{p}_{A}=0.75=\mathrm{p}_{c}$. Recall that eqs. (4) and (5) correlate the conversion of hydroxyl and acid moieties as functions of oxirane conversion.

\section{Sol Fraction}

Relationships partitioning a monomeric link between the sol and gel are now derived. The mol fraction of branch nodes in the sol is labeled vOX. The fraction of branch nodes in the gel equals 12 vOX. For a chain link to be in the sol, each of its reactive sites must be part of finite chains. Therefore, the fraction of epoxy units including the monomer in the sol equals

$$
\omega_{O X}=\left[P\left(\Gamma_{O X}^{\mathrm{x}}\right)\right]^{2}
$$


R. M. Tadros, H. Noureddini, D. C. Timm, Z-Protected Glutamic Acid-Based Biodegradable Thermoplastic and Thermosetting Polyesters: Synthesis and Characterization

The mol fraction of connecting links in the sol equals

$$
\omega_{A}=\left[P\left(F_{A}\right)^{\text {out }}\right]^{2}
$$

The mass fraction of the resin that is soluble is

$$
\operatorname{mass}_{\mathrm{sol}}=\frac{M W_{o X} \alpha \omega_{O X}+M W_{A} \omega_{A}}{M W_{o X} \alpha+M W_{A}}
$$

where the molecular weights of the epoxy monomer and $\mathrm{ZGluOH}$ are $M W O X$ and MWA.

\section{Branch Node Distributions}

In the theory of rubber elasticity, the modulus of elasticity is a function of the number of elastically active junctions that contain three or more chain extensions to the gel. ${ }^{28,29}$ Thermoset resins become elastomeric at temperatures exceeding their glass transition temperature $\mathrm{Tg}$. For our resin systems, branch nodes evolve from the diepoxy monomers and are labeled $n_{R O X, R O H}$. The initial index $0 \leq R O X \leq 2$ indicates the number of oxiranes reacted and the second index $0 \leq R O H \leq R O X$ indicates the number of hydroxyls formed that have reacted. In conversion space, a series of first-order reactions associated with the formation and consumption of nodes yields their mol fractions:

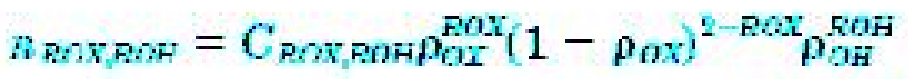

$$
\begin{aligned}
& \times\left(1-p_{A H}\right)^{\text {BOX-POH }}
\end{aligned}
$$

where the coefficient $C_{R O X, R O H}=1$ unless $R O X$ and/or $R O H=1$, then $C_{R O X, R O H}=2$. Kernels address the reaction states of the two functional groups, and, as appropriate, their powers equal the number of these sites reacted or unreacted. Subject to reaction constraints and normalization, the coefficient correlates permutations. Crosslinks $X m, 0$ that contribute to the modulus are nodes that contain a minimum of three chain 
R. M. Tadros, H. Noureddini, D. C. Timm, Z-Protected Glutamic Acid-Based Biodegradable Thermoplastic and Thermosetting Polyesters: Synthesis and Characterization

extensions to the gel or network. Such chains are considered to be infinite.28,29 The initial subscript is the number of reacted sites, and looking out of the node, the second subscript is the number of these sites attached to the network. Since each reacted site is attached to a bifunctional link, the probability that it extends to the gel is $12 P$ (FA out). The normalized molar concentration of elastically active nodes equals26:

$$
\begin{aligned}
& X_{3,3}=n_{2,1}\left[1-P\left(F_{A}^{\text {out }}\right)\right]^{3} \\
& X_{4,3}=n_{2,2} 4 P\left(F_{A}^{\text {out }}\right)\left[1-P\left(F_{A}^{\text {out }}\right)\right]^{3} \\
& X_{4,4}=n_{2,2}\left[1-P\left(F_{A}^{\text {out }}\right)\right]^{4}
\end{aligned}
$$

\section{Analysis of Relative Rate Constant}

The conversion of carboxylic acid and the sol fraction for the crosslinked ZGluOH/BDE/PTS sample cured for $1112 \mathrm{~h}$ at $130^{\circ} \mathrm{C}$ was 76 and $80 \%$, respectively. Subject to model constraints and assumptions, eqs. (6)-(15) were solved with eqs. (4) and (5) to determine the value for the relative rate constant $C$. When $C 53.0$, the calculated sol mass fraction is $81 \%$, and conversions $\mathrm{rOX}$ and $\mathrm{rOH}$ equal 0.47 and 0.60 when $r A$ is 0.76 . The rate constant for carboxylic acid reactions with oxiranes is smaller than that with hy

droxyl moieties; tetrafunctional chain segments have a preference for branching. The molecular theory of rubber elasticity28,29 predicts that a resin with more elastically active junctions will have a higher modulus at temperatures above $\mathrm{Tg}$. The resin produced was rubbery, indicating a relatively low level of crosslinking. For the crosslinked ZGluOH/DGEBA/PTS polymer sample cured for $5 \mathrm{~h} 40 \mathrm{~min}$ at $130^{\circ} \mathrm{C}$, the average value for the acid's conversion was $68 \%$ and the sol fraction was 0.50 . For a solution with $C 5200$, a sol fraction of 0.51 subject to conversions $\mathrm{r} A 50.68, \mathrm{rOH} 50.99$, and $\mathrm{rOX} 50.36$ was calculated. Not only did this resin contain a chain-stiffening, aromatic component within its chain links, but the conversion of hydroxyls to esters also was nearly complete. A high degree of branching and crosslinking occurred. The resin was brittle at ambient temperature.

\section{Crosslink Distributions}

To further characterize the network structure, the relative distribution of nodes that contribute to the modulus and other physical properties was calculated. Subject to experimental measurements of conversion and regression estimates of $C$, the fraction of tetrafunctional branch nodes with three or four extensions to the gel for the resin ZGluOH/BDE/PTS is X3,3 $57.131025, X 4,359.331025$, and $X 4,45$ 1.131025 , and for the resin ZGluOH/DGEBA/PTS, X3,3 $54.131025, X 4,353.131023$, and X4,451.5 3 1023. Although both resins contain a relatively large sol fraction due to an imbalanced stoichiometry and low extent of conversion, the results clearly demonstrate the increased level of network branching in the latter resin. The large value for the relative rate constant $C$ results in a ratio of $X 4,4 / X 4,350.5$ in the resin composed of aromatic chain links (compared to 0.1 for the first thermoset). These numbers show that when an oxirane reacts the formed hydroxyl group is converted to an ester bond at once, forming a branch point in the chain. This chemistry leads to network configurations.

\section{DISCUSSION}


R. M. Tadros, H. Noureddini, D. C. Timm, Z-Protected Glutamic Acid-Based Biodegradable Thermoplastic and Thermosetting Polyesters: Synthesis and Characterization

A major research objective was to produce quality thermoplastic and thermoset resins from an amino acid. The results of our studies indicate that the thermoplastic resin formulated from ZGluOH/EG/PTS had an average molecular weight of 22,000. Many commercial step-growth resins have similar average molecular weights. Analysis of the thermosetting resins identified their respective gel fractions at a final conversion.

These data were incorporated into gelation theory to calculate the relative rate constants for reactions involving oxiranes and alcohols with carboxylic acids. Results indicate that the two rate constants are not equal and that their relative magnitudes are influenced by the chain structure. These observations are consistent with observations for amine-cured epoxies. Aliphatic or aromatic segments significantly alter the reactivities of primary and secondary amines.18 Furthermore, chemical analysis of chemical intermediates in a curing anhydride/epoxy resin20 revealed that the alcohol moiety is many times more reactive than is the acid group. Our results are also consistent with their observations. For resin systems described by Cole's model for diminishing reaction rates at higher conversions, the relative rate constant $C$ incorporates these effects when the constants a for the oxirane and alcohol reactions are equal. The network chemical structure that contributes to the rubbery modulus of elasticity was estimated through branch-node distributions. The results reveal the effects of the conversion and the relative magnitudes for the distinct rate constants.

In the ZGluOH/EG/PTS resin, branch points tend to be farther apart. The crosslink average molecular weight of elastically active strands is greater than that for the ZGluOH/ DGEBA/PTS resin. Increased chain flexibility caused by the chemical structure within the chains and the higher crosslink average molecular

weight yield a ductile resin at room temperature. The increased chain stiffness caused by aromatic components within the chain links and the lower crosslink average molecular weight contributed to a brittle resin in

the second case. In companion articles, the biodegradability of these three resins is reported. In summary, lipase hydrolized all three resins to the monomers, but in the presence of a mixed microbial culture, only the resins ZGluOH/EG/PTS and ZGluOH/BDE/ PTS were reduced to biomass and respiratory gases.

Financial support from the Nebraska Soybean Development, Utilization and Marketing Board, the Center for Materials Research and Analysis, and NRI funds for Reaction Engineering Strategies to Produce Valueadded Chemicals from Agricultural Feedstocks, University of Nebraska-Lincoln, is appreciated.

\section{REFERENCES}

1. Fried, J. R. Polymer Science and Technology; Prentice-Hall: Englewood Cliffs, NJ, 1995; p 244.

2. Paetau, I.; Chen, C.-Z.; Jane, J.-L. Ind Eng Chem Res 1994, 33, 1821.

3. Dechow, F. J. Separation and Purification Techniques in Biotechnology; Noyes: Park Ridge, NJ, 1989; pp 268, 273, 386.

4. Fox, S. W.; Foster, J. F. Introduction to Protein Chemistry; Wiley: New York, 1957.

5. Lee, K.; Hong, J. Transport of Amino Acids Through Ultrafiltration Membranes in the Presence of an Electric Field; Lee, K.; Hong, J., Ed.; AICHE: New York, 1992; Bull. 290, p 72.

6. Anderson, J. M.; Gibbons, D. F.; Martin, R. L.; Hiltner, A.; Woods, R. J Biomed Mater Res Symp 1974, 5, 197.

7. Sato, H.; Noishiki, Y.; Chen, G.; Hayashi, T.; Nakajima, A. Novel A-B-A Block Copolymer Consisting of Poly(g-ethyl L-glutamate) (A) and Polybutadiene (B) as Biomaterial; Kyoto University: Kyoto, Japan, 1984; \#07929, p 87.

8. Lenz, R. W.; Kin, Y. B.; Fuller, R. C. J Bioact Compat Polym 1991, 6, 382.

9. Jones, J. Amino Acid and Peptide Synthesis; Oxford: Oxford, UK, 1992; pp 14, 23, 45. 
R. M. Tadros, H. Noureddini, D. C. Timm, Z-Protected Glutamic Acid-Based Biodegradable Thermoplastic and Thermosetting Polyesters: Synthesis and Characterization

10. Cyclic Polymers; Semlyen, J. A., Ed.; Elsevier: London, 1986.

11. Albert, A. Heterocyclic Chemistry, 2nd ed.; Athlone: London, 1968.

12. Pramanick, D.; Rey, T. T. Polym Bull 1987, 18, 311.

13. Stevens, M. P. Polymer Chemistry: An Introduction, 2nd ed.; Oxford University: Oxford, UK, 1990; pp 440-446.

14. Carothers, W. H. Chem Rev 1931, 8, 367.

15. Nielsen, J. A.; Chen, S. J.; Timm, D. C. Macromolecules 1993, 26, 1369.

16. Tadros, R.; Timm, D. C. Macromolecules 1995, 28, 7441.

17. Flory, P. J. Principles of Polymer Chemistry; Cornell University: Ithaca, NY, 1953.

18. Rozenberg, B. A. In Advances in Polymer Science, Epoxy Resins and Composites; Dušek, K., Ed.;

Springer-Verlag: Berlin, 1986; Vol. 78, p 113.

19. Cole, K. C. Macromolecules 1991, 24, 3093, 3098.

20. Antoon, M. K.; Koenig, J. L. J Polym Sci 1981, 19, 549.

21. Stockmayer, W. H. J Polym Sci 1952, 9, 69.

22. Blatz, P. J.; Tobolsky, A. V. J Phys Chem 1945, 49, 77.

23. Bokare, U. M.; Gandhi, K. S. J Polym Sci Polym Phys Ed 1980, $18,857$.

24. Gupta, A. M.; Macosko, C. W. J Polym Sci Part B Polym Phys 1990, 28, 2585.

25. Sarmoria, C.; Miller, D. R. Macromolecules 1991, 24, 1833.

26. Robbins, D. J.; Timm, D. C. Macromolecules in press.

27. Dušek, K.; llavsky', M.; Luña’k, S. J Polym Sci Polym Symp 1975, 53, 29.

28. Dotson, N. A.; Galvan, R.; Laurence, R. L.; Tirrell, M. Polymerization Process Modeling; VCH: Cambridge, UK, 1996.

29. Mark, J. E.; Erman, B. Rubberlike Elasticity: A Molecular Primer; Wiley: New York, 1988. 